\title{
DEVELOPMENT OF SOCIAL PSYCHOLOGY IN JAPAN
}

\section{KIMIYOSHI HIROTA}

Kansai University

Japanese social psychology has a history of half a century. As to publication of social psychological works, however, most spaces of the journal, Japanese Journal of Psychology are occupied by articles of such experimental psychology as perception, learning, etc. and least is allocated to social psychological works, losing opportunities to be published due to lack of specialists in the field. Under these circumstances many excellent studies have been left unnoticed utterly or made public only through such rather restricted channels as separate reports of individual universities which are hardly available. For this reason, in this brief report, and partly because the space permitted to the writer is quite limited, attention is rather focused on the general trend in the whole social psychology and highlighted features of its development rather than detailed comments and references to individual works. In this respect eager readers who want to get detailed information on individual studies might complain, though the writer may give them his promise to review some outstanding works somehow when he can have another opportunity in the near future. The readers are requested to bear in mind that the writer had arbitrarily to exercise ruthless selectivity in choosing what is to be included in this review.

\section{General Survey of the Pre-War Social Psychology of Japan}

Our first use of the term "social psychology" or publication of the book thus entitled dates way back to almost the same days of the American social psychology. For example, the first book entitled Social Psychology by K. Higuchi was published in 1908. Thereafter came the 12-year early blooming days of the opening stage of Japanese social psychology, when 14 social psychological works entitled Social psychology, Group psychology, Racial psychology, etc. were published, a period which had lasted until 1920. It is, however, to be regretted that during this period almost no psychologists participated in creating this uptrend except $\mathrm{Y}$. Kuwata, who wrote in the manner of typical Wundtian folk psychology Group Psychology (1917), and Folk Psychology of $W_{\text {undt }}$ (1918). Other works were almost solely elaborated not by psychologists but sociologists and social philosophers, consequently they were filled with metaphysical and ideological thinking without scientific data and assumed very much the appearance of introductory books to the then European social sciences. Considering the fact that it was as late as 1927 when the first annual convention of the Japanese Psychological Association was held and our scientific psychology got started, and until then being a branch of imported German philosophy it had limited along in rather singular circumstances, it was natural that most works were carried out by philosophers until about 1920. In those days in Japan psychology as well as sociology was regarded as a branch of philosophy, consequently any scholars investigating psychological problems were usually thought to be philosophers.

Between 1920 and 1930 only seven (known to the writer) books on social psychology were published. It was during this period that the methodology imported by Kuwata and others 
-although this was the German ideological way of thinking called Wundtian folk psychology - worked out the groundwork for studying empirical social psychology. We might call this period the Formative Stage of Japanese social psychology.

The fifteen years between 1930 and 1945 had a dual characteristic. First, quite a few scientific and experimental analyses came out to the extent that this period seemed to be the stage of experimental study, in contrast to the scarcity of the number of issued books on social psychology, though in 1942 Social Psychology and Racial Psychology written by many psychologists and edited by M. Matsumoto appeared. Second, since militaristic control by the government and the authorities was getting increasingly powerful and to study social sciences was becoming taboo and it was hardly possible to study social psychology systematically, scholars were tended to be forced to be satisfied rather in only maintaining social psychological study by unharmful experimental analyses than to challenge the authorities by writing systematized social science books. Additionally, such journals mainly devoted to experimental social psychology as Journal of Abnormal and Social Psychology, Journal of Social Psychology, etc. were abundantly imported and scholars were increasingly getting contact more and more with the then newest experiments conducted by American psychologists and through this channel they were motivated to do experimental works, being offered an opportunity to check methodology of social psychology. For these two reasons this period was destined to feature a good number of enthusiastic experimental analyses.

In the latter half of the thirties the Handbook of Social Psychology edited by C. Murchison was imported, the fourth section of which entitled Experimental Constructions of Social Phenomena had exerted a deep influence upon Japanese social psychologists. Centering around the problems of competition and cooperation in the so-called problem-solving process, experimental analyses had made rapid progress to the extent that we might safely say that building up social psychology solely by psychologists was completed. Articles on experimental social psychology began to show up in Japanese Journal of Psychology, which is the oldest psychological journal in Japan (and its fifth volume was being issued in 1930). Reference should be made to some papers in this journal. H. Matsumoto made an experimental analysis (48) (49) of social influences by examining how discussion process would be influential upon a member's opinion, and $\mathrm{H}$. Kaneko et al. reported an experimental analysis of the types of classes in a primary school measuring friendship relations by sociometry (28). As to leadership, K. Toki's pioneering field study (91) which was cited in their Fundamentals of Social Psychology by E. L. Hartley and R. L. Hartley (1952), reported on dynamic process of reorganization and collapse of a follower group which occurred under the conditions of isolating the leader in leader-follower relations in a classroom situation, and S. Kamitake (26) (27) took up a series of genetical studies of leadership in a child group. They thus laid a groundwork for experimental psychology of leadership.

Another thing, the fact that check-up on methodology of social psychology was gradually getting more and more prevalent was illustrated by popular discussions on how American experimentalism was to be incorporated into the traditionally German-influenced Japanese psychology (36) (37). This period, then, was characterized also by many polemic and counterpolemic discussions at various psychological meetings and in articles, for example (37) (38) by 
T. Kondo, by H. Kano (30) and the like. Investigations of competition and competitive situations from the standpoint of individual level of aspiration as well as check-up on such measurement methodology as the applicability of various attitude measurements and survey methods (23) (35) were made.

Generally speaking, during this period the scientific way of thinking had pervaded in almost the whole area of social psychology. Most works were, however, merely on a tentative basis and the then general tendency was that researchers were not pursued organizedly nor followed and checked by colleagues, that is, this was a stage in which scholars picked up a topic arbitrarily as his own interest would stray, and tested it out experimentally. It is quite conceivable that without the war this stage would have been a turning point to the developmental stage in which many following studies could have been worked out, whereas our social psychology which suddenly burst into blossoms withered away at this critical juncture when the cold wind of militarism began to blow around 1940. We can point out another feature of social psychology in this period, which was the fact that there had been few works carried out by experts specializing in social psychology. Until then Japanese psychology had developed along the general line of Wundt-to-Gestalt German psychological approach and almost all our psychologists had been exclusively engaged in laboratory experimental psychology of perception and learning. Most social psychological studies were conducted by experimental psychologists as byproducts of their intrinsic works, whose interests were originally focused upon problems of perception. It was quite difficult to find out a single social psychologist who was pursuing a social psychological study and declared himself to be clearly and distinctively a social psychologist.

From then on Japan had leaped into the dark tunnel of the war, which wielded devastating power on the young Japanese social psychology. Social science was a taboo. Except for aviation psychology, scientists were never permitted to get into the broad area of army organization, of soldier groups, or human relations in the Army. The writer guesses the readers would surely get confused to compare these situations during the war with those in America in which a great practical contribution was made by social psychologists to improvement of human relations in army social groups and they could affirm the versatility and importance of the science of interpersonal relationship. To prohibiting criticism upon Japanese Army to maintain its bizarre esprit de corps it would have been necessary for the authorities as a part of its war-time gag-law policy to suppress social sciences.

\section{“Great Leap Forward” of Social Psychology in Post- War Years}

The trends of pre-war social psychology described above utterly changed just after the war. It could rather be said that completely a new social psychology developed tremendously in scope, than to say that the pre-war trends were inherited by post-war Japanese psychology. The reasons are: (1) We could begin to study social psychology freely because the study of whole branches of sciences was liberated after the war from any constraints and suppressions. (2) Drastic changes in social structures and a tremendous shake up of social classes on account of the defeat produced whole-scale individual maladaptations to various social situations, which swept over Japan and caused so-called mass maladaptations. Being stimulated by approved importance and practicability of the science of interpersonal relationships between 
individual human beings in society, reorganizing a new social hierarchy by introducing democracy, it was natural that practical social psychology should have been urgently needed on this occasion. Incidentally, it is said that learning theory, clinical psychology, and our social psychology are the most advanced fields after the war in Japanese psychology. It seemed that one of the reasons for rapid progress in the latter two branches was an urgent need for them to dispose social disorders which shook Japan just after the war and had never been experienced by the Japanese people. (3) It became possible to restore communications with the outer world and to get new research methods, theories, and data. Isolation from psychologists in the world during the war had been fatal to Japanese psychologists more or less under the influence of western psychologists. Gradually securing communications with psychologists across the world, their intolerable thirst for new knowledge, especially for American social psychology, of which developments in the area of experimental research and the relatively quite high level of its systematization seemed enough to astound Japanese psychologists.

The newly experienced trends that many social phenomena, until then just having been looked on unconcernedly by them as belonging to other branches of sciences were being handled and systematized beautifully to be incorporated into the system of social psychology, and that quantification of social phenomena previously regarded as being impossible of exact measurement seemed to be possible, were enough to stimulate Japanese psychologists to social psychology. (4) It has become the general tendency to promote unification and cooperation between neighboring sciences in the social sciences. As mentioned earlier, social psychology had been byproducts of psychologists' (more exactly, experimental psychologists') intrinsic works. With the advent of the new educational system and sudden increase in number of young scholars specializing in psychology, many genuine social psychologists appeared, being motivated by the circumstances previously described. Many sociologists, meanwhile, as well as psychologists have become inclined to specialize in social psychology by developing methodology of traditional psychological sociology into new direction. The first book on social psychology after the war was Social Psychology by H. Minami (1948), who had stayed in the U. S. during the war, which introduced new systems of social psychology to Japan and deserved the merit to be called an "eye-opener."

The author of famous "Social Psychology" (1951), on the other hand, was I. Shimizu, who was a genuine sociologist. Thereafter, the rate of the numbers of psychologists and sociologists in social psychology has been as 70 to 30 , who have been endeavoring in systematizing social psychology cooperatively and complementarily on the common basis. Moreover due to the great development of cultural and social anthropology imported from America, psychologists, sociologists, and cultural anthropologists began to pursue their subjects further through the interdisciplinary approach and highly contributed to the rapid advancement of social psychology. Currently, the Japanese Psychological Association has about 2,000 members of which $10 \%$ could be considered to be experts in social psychology. Besides these legitimate social psychologists, all scholars studying social psychology in various sociological and anthropological association taken together, it is quite conceivable that about 3oo scholars are exclusively engaged in studying social psychology. 
At the present along the line of integrating social sciences, being stimulated by American way of thinking, there exists a general feeling that cooperation and coordination among scholars belonging to various fields are indispensable to establish the science of a social man or the unified behavioral science.

Seeing the circumstances described above, Japanese social psychology seems to have entered an age of renaissance and gets highlighted brilliantly as a glamorous prima donna of the Japanese Psychology troupe on the stage. Here we had better examine the present stage of our social psychology in slightly more detail.

\section{Activities of Psychological Associations}

Currently the most important psychological associations in Japan are the Japanese Psychological Association, the Japanese Applied Psychology Association, and seven regional associations. Let us just see the activities of social psychologists at the conventions in the last ten years (Table 1). By just glancing at the table readers would notice the yearly uptrend of the number of social psychological papers. Readers are requested to be aware that the number of social psychological papers indicated below is those read only in the social psychological section and that there are also a number of social psychological studies besides those papers, in the sections of educational psychology, developmental psychology, industrial psychology, and clinical psychology. Moreover, considering many social psychological papers read at the annual convention of the Japanese Applied Psychology Association plus those at regional psychological societies, one might fairly say that over one hundred reports are being yearly produced. On the occasion of the 1955 convention of the Japanese Psychological Association, to set up a nation-wide organization of social psychologists there was organized the Society for Social Psychological Study which has at the present time about 200 members. We can expect rapid progress in social psychology by publishing Annual Report of Social Psychology of this society in 1959 , and hereafter.

\section{Trends of Research}

Let us analyse the subjects appearing at the conventions from 1950 to 1959 . The three categories are set up to make an analysis:

(1) Individual Process: The subjects centering around individual behavior and experience in social contexts such as personality and social character, social attitude, and socialization, etc. (2) Group Process: Includes interaction and communication in a group, person perception, interpersonal perception, group cohesiveness, productivity, group structure and function, role and status, leadership, etc. Otherwise known as "Group dynamics."

(3) Social Process: Psychological analysis of the more conclusive social phenomena including cultural and institutional behavior, mass communication, etc.

(4) Check-up on research methods of social psychology:

Table 1 Number of Social Psychological Papers Read at the Conventions of the Japanese Psychological Association in Recent Ten Years.

\begin{tabular}{lrrrrrrrrrr}
\hline & 1950 & 1951 & 1952 & 1953 & 1954 & 1955 & 1956 & 1957 & 1958 & 1959 \\
\hline Total number of papers & 301 & 336 & 339 & 388 & 492 & 506 & 516 & 530 & 653 & 480 \\
Social psychological papers & 20 & 27 & 42 & 35 & 54 & 49 & 64 & 50 & 59 & 44 \\
\hline
\end{tabular}


Table 2 shows the results of this analysis.

Table 2 The Subjects of Social Psychological Papers Read at the Psychological Conventions in Recent Years.

\begin{tabular}{|c|c|c|c|c|c|c|c|c|c|c|c|}
\hline & & 1950 & 1951 & 1952 & 1953 & 1954 & 1955 & 1956 & 1957 & 1958 & 1959 \\
\hline \multirow{3}{*}{$\begin{array}{l}\text { Individual } \\
\text { process }\end{array}$} & Personality & 2 & 3 & 4 & 3 & 9 & 3 & 14 & 5 & 8 & 4 \\
\hline & Attitude & 3 & 2 & 7 & 6 & 11 & 6 & 5 & 4 & 12 & 6 \\
\hline & Socialization & 2 & 4 & 3 & 2 & 3 & 0 & 4 & 6 & 2 & 0 \\
\hline \multirow{3}{*}{ Group process } & Person perception & 0 & 0 & 0 & 0 & 1 & 0 & 2 & 4 & 3 & 6 \\
\hline & $\begin{array}{l}\text { Group structure } \\
\text { and function }\end{array}$ & 4 & 4 & 8 & 5 & 8 & 14 & 14 & 8 & 10 & 4 \\
\hline & $\begin{array}{l}\text { Role and status } \\
\text { leadership }\end{array}$ & 1 & 1 & 1 & 0 & 3 & 4 & 4 & 0 & 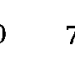 & 1 \\
\hline \multirow[t]{2}{*}{ Social process } & $\begin{array}{l}\text { Cultural and } \\
\text { institutional } \\
\text { behavior }\end{array}$ & 4 & 5 & 14 & 12 & 11 & 14 & 11 & 7 & 9 & 9 \\
\hline & $\begin{array}{l}\text { Mass communi- } \\
\text { cation }\end{array}$ & 3 & 3 & 3 & 6 & 4 & 7 & 8 & 13 & 3 & 12 \\
\hline $\begin{array}{l}\text { Research } \\
\text { method }\end{array}$ & & 1 & 5 & 2 & 1 & 4 & 1 & 2 & 3 & 2 & 2 \\
\hline Total & & 20 & 27 & 42 & 35 & 54 & 49 & 64 & 50 & 59 & 44 \\
\hline
\end{tabular}

Readers are requested to bear in mind, firstly, that in this table though the subjects of personality, attitude, and socialization, etc. could be seen in pre-war days also, the contents of which has quite changed, for example there appeared after the war problems of how changed were the personalities of Japanese people who managed to get through the havoc just after the war, attitudes towards war or the atomic bomb, ethnic prejudice, analysis of social characters in the Japan's feudal society simulating the study of "Authoritarian Personality" by Adorno, A. W. et al., and social adaptation and personality of hybrid children between GIs and Japanese women. An arduous search for various conflicts and gaps between the adult and younger generation by analyzing attitudes of Japan's youth multidimensionally is one of the most outstanding posts marking the boundary between pre- and post-war investigations. These studies bore the fruits of the reports by H. Minami (55) and T. Fukutake (13) on social characters of Japanese people.

Secondly, studies on group process have suddenly become much in vogue since the defeat. By introducing such new studies as those at the Research Center for Group Dynamics, Festingerian theory of informal communication, methodology of group dynamics, researches in this area have gotten quite refined. Some of the reasons for these circumstances are the rigidity and exactness of fairly controlled laboratory experiments of group dy.amics, which were enthusiastically welcomed by Japanese psychologists who always claim rigorous exactness of laboratory researches from psychology, and that it was just the time when a guidance method of the small group was urgently needed in actual situations in school. It might be conceivable, however, that, a hidden reason was the fact that, for poorly financed Japanese psychologists it was much easier to make a small-scale and economical experiment than 
do a field research. It was these circumstances that boosted the development of group dynamics greatly.

Group dynamics is very promising. At the present, after the long imitating period, we are entering on the new stage of liquidation of imported group dynamics, where we must secure the unique Japanese group dynamics considering our specific cultural factors, group properties, and personal factors. Another outstanding feature of the works at the time on group process is that experimental analysis of person perception made its début upon the stage in 1956. It may safely be assumed that this would be a very promising field being inspired by "Theories of Person Perception" of F. Heider, R. Tagiuri, W. C. Schutz, et al-

Thirdly, there are two remarkable things in the investigation of social process. One of them, which is in the field of cultural and institutional behavior, is that by introducing new research methods of cultural anthropology after the war, survey methods collecting data for the study of an inhabitant group of an isolated island, a closed community, a minority group have got quite advanced and become practical. The studies that how deep Japanese cultural tradition exerts influence on individual behaviors and what are the socio-behavioral products of conforming to social norm have been, which had been main subjects in pre-war days also, quite has got renovated after the war, featuring scientific study based on field surveys, shaking off old sociological research methods.

The upsurge of the study of mass communication must also be mentioned, which is the most outstanding character of the recent social psychology since $1950 \mathrm{in}$ Japan. The developments of group dynamics and the study of mass communication seem to be the most remarkable features of our post-war social psychology. The range of the research of mass communication, however, had been roughly limited to content analysis and effect analysis of newspapers until 1955 and since then general tendency in researches has been tended to analysis of electric communication. One of the reasons for this trend is to control the sudden upheaval of war-cries of great numbers of commercial radio and TV broadcasts (currently in large towns 1 radio set for 1.1 homes and 1 TV set for 4.2 on an average) and that gradually there appeared violent discussions on the influence of electric communication upon children's minds, and misbehaviors of a so-called television child have been regarded as quite menacing. At the present time many Japanese original studies are being worked out mainly in the field of comparative studies of the effects of printed media, radio, and TV through effect analysis, experimental approach of the Yale Group guided by C. I. Hovland and study of personal influence pursued by P. F. Lazarsfeld.

\section{Post-War Trends Appearing in Various Pubitcations}

Post-war activities began with checking social psychological concepts of $\mathrm{K}$. Lewin, methodology of new social psychology, and in the field of experimental presentation on Lewinian leadership styles (1) (22) (34) (82) (83) (84). The reasons for these circumstances are that experimental analysis of $\mathrm{K}$. Lewin's group atmosphere seemed to contribute psychologically to post-war democratization of Japan and reorientation of social psychology, and his field theory was relatively easy to be accepted by Japanese psychologists who had been trained in Gestalt psychology. This trend has gradually yielded to genuine experimental studies, a forerunner of which was attitude change measurement by K. Sato and F. Nakane (78). They 
explored significant differences between pre- and post-war racial preferences of Japanese students and ascertained the effects of war upon them.

Since 1950 most studies shown up in psychological journals have been works on group dynamics and laboratory experiments of social perception. The latter, however, being introduced into Japan as the new-look psychology of J. S. Bruner and others, this subject has been pursued for the most part by psychologists specializing in the study of perception. On the other hand most social psychologists have been tending to the study of group. Quite a few experiments on group process stimulated by experiments and hypotheses of Festingerian informal communication introduced by $\mathrm{K}$. Hirota and others to Japan and by experimental analyses by experts in group dynamics chiefly at the Research Center for Group Dynamics have been published. Here the writer only refers to some important works on this subject because on account of the lack of space he can not comment on them in detail and at another place in this issue J. Misumi is epitomizing development of Japanese group dynamics (14) (15) (16) (29) (32) (58) (59) (61) (65) (72) (73) (74) (77) (93).

Interaction process analysis of R. F. Bales also has been adopted broadly by Japanese psychologists for observation of discussion groups and analysis of interaction between parents and children (62). Recently the problem of interrelationship between friend choosing and person perception has been taken up experimentally and a series of studies of empathy in child groups by M. Ohashi has been published (68) (69) (70).

There are two trends in the study of social attitudes. One is factorial analysis of the constituents of social attitudes of the Japanese younger generation by various Thurstone scales conducted by K. Tanaka and others (12) (50) (85) (86) (87). Another thing is many explorations, for example (16) by K. Hirota and (66) (67) by A. Nomura, in cultural, social and behavioral factors of prejudice toward minority groups by majority groups in Japan. K. Tanaka et al. (88) suggest a new direction in Cattellian factor-analytical study on Japan's culture. Attitude analysis by Guttman scale is also an active area.

In the area of measurement sociometry has got tremendous popularity after the war and almost all scholars studying social groups, and school class educational-psychologically are using it and tentative works on morale of a work group in industry through sociometric approach have gradually been shown up. At the present the human relation approach in industrial psychology has quite advanced in Japan. The most representative work in this region is (33). Incidentally few papers on sociometry are shown up in the journals of psychological associations, most works, meanwhile, on this subject appear in such monthly commercial educational science journals as Child Study and others.

Recently there appeared a vicious trend to use sociometry easily beyond the scientifically reasonable limits and some scholars are giving it careful reconsideration and checking on abuse of sociometry (18) (90). In the field of mass phenomena, studies on rumor (31), political behavior (47) (71), and mass communication (24) (64) are worth mentioning here. The first issue in 1959 of Japanese Psychological Review featured the study on mass communication in which $\mathrm{H}$. Ikeuchi reviewed the present and future trends in the study of mass communication (21).

In book form, H. Minami (54) (56), Y. Ito (25), I. Shimizu (80), O. Miyagi (57), 
T. Kondo (39), T. Sotobayashi et al. (81), J. Abe (2), H. Chiwa (Ed.) (8), and others wrote text books of social psychology. In the field of group dynamics a series The Study of Group Dynamics of which four numbers have already been published by the Kyushu Group Dynamic Center to systematize this science. The two popular books entitled Psychology of Society and Culture and Psychology of Politics and Economics of the six-volume series Contemporary Psychology (1955, Kawade Pub. Co.) contributed much in stimulating layman's interest in social psychology. Since 1958 the 'Handbook of Social Psychology' (Nakayama Pub. Co.) in eight volumes by social psychologists, sociologists, cultural anthropologists has been and is still being published and in curren 1959 yexr publication of the Handbook of Applied Social Psychology, (Kobunsha Pub. Co.) three volumes of which have already been out, edited by H. Minami is now in progress. Eight volumes of Handbook of Social Psycho$\log \gamma$ are entitled respectively: 1. Foundations of social psychology. 2. Social man. 3.Psychology of human relation. 4. Psychology of mass phenomena. 5. Psychology of abnormal social behavior. 6. Psychology of cultural phenomena. 7. Psychology of political and economic behavior. 8. Psychology of social class and social movement. Each of them was written cooperatively and organizedly by experts on respective important topics. As for the study of mass communication the Handbook of Mass Comnunication (Kawade Pub. Co.) in six volumes were published in 1955. In the field of social psychological study of the child group there are (60) by S. Nagashima and K. Tanaka (89).

Translation works in social psychology are (3) by G. W. Allport, K. Lewin (41)(42)(43), D. Cartwright and A. Zander (6), G. Lindzey (44), H. Cantril (5), T. M. Newcomb, (63), R. Centers (7) which have already been translated into Japanese, and (4) by S. E. Asch, N.R.F. Maier (51), C. I. Hovland (19), M. Sherif (78) which are now in progress. We can not overlook such very stimulating translations as (9) (10) (11) by E. Fromm , G. C. Homans (19), T. Parsons (75), D. Rieseman (76), C. W. Mills (52) (53), H. D. Lasswell (40), R. Linton (45) (46) out of the social psychology proper.

\section{Activities of Japanese Social Psychologists.}

In Japan social psychologists are not under very favorable conditions. Most social psychologists belong to psychology, sociology, or journalism department etc. at main universities whereas under present circumstances the courses in social psychology are accessory to general psychology courses and there exists no full program in Japan designed exclusively to raise experts in social psychology. After the war quite a few students have popped up who conduct experiments and social psychological survey for their theses, however, compared with the number of students of experimental psychology they are quite few in number, and only poor laboratory facilities are available for them. Deeply motivated personally towards social psychology, defiant students are left alone to get social psychological knowledge and techniques independently using poor facilities under the insufficiently reorganized new education system.

A number of excellent young social psychologists, however, have infiltrated into business answering a recent great demand for social psychologists in general industry, mass communication industory, social case work and the like. 
One more word to mention activities of social psychological institutions. In Tokyocentering around the Institute of Journalism at Tokyo University scholars are producing excellent theoretical and experimental works on political and economic behavior and mass communication, and at Kyoto University peoples are cooperatively pursuing the subjects of racial prejudice and international communication and understanding under the leadership of Prof. K. Sato and sponsored by UNESCO. Prof. Sato has also established the Center for Ethology for integration and reorganization of social sciences based on comparative behavioristics through interdisciplinary approach, where he is the leader of such social psychological projects as exploration in suicide etc., At this center being integrated in one group, psychologists, sociologists, educational scientists, psychiatrists are planning to do cooperatively their jobs on the common basis, which is worth being appreciated as to represent a recent pronounced trend in Japan of integrating social sciences. At this university the Human Relation Research Institute in Industry also has been set up, where sociologists, administrators, social psychologists, and industrial psychologists are cooperatively pursuing their subjects of human relations scientifically. At Kyushu University led by staff members at the Kyushu Group Dynamics Center many scholars are engaged in works on applied group dynamics as a subject in social engineering.

At other educational institutions also, of course, in Japan young scholars are carrying on their works, discussing the matter, being organized in study groups.

To make a long story short, Japan's social psychology has just got reorientated in post-war Japan from the old metaphysical or descriptive social psychology to scientific social psychology based on experimentation. At the present it seems that just after finishing the tough work of digesting American social psychology it would come out in future that this science would firmly root in Japan and be organized after sufficient analyses of character of Japanese culture and society. And by the great diligence and endeavor of Japanese scholars the foundations for things to come in the very rosy future has already been firmly established and it would be a reasonable expectation that their efforts could bear delicious fruits. The only threatening cloud on this occasion is would-be war-time suppression upon free study of social phenomena by free activities of scholars and communications with foreign scholars which was acquired after a long struggle. Meanwhile it is natural that we do hope that the time would come when we can be proud of our own unique works, shaking off imitations and follow-up of foreign studies. In this sense to prevent a war, remove prejudices, and live thrivingly in a peaceful world we do hope that also we social psychologists can pursue our subjects cooperatively on the world-wide basis.

\section{REFERENCES}

$\star \star$ 1. Abe, J. Social psychological approach to culture. Jap. J. Psychol., 1949-50, 20, 16-21.

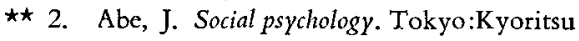
Shuppan, 1956.

3. Allport, G. W. \& Postman, L. The psychology of rumor. New York: Henry Holt, 1947.

4. Asch, S. E. Social psychology. New York:
Prentice-Hall, 1952.

5. Cantril, H. The psychology of social movement. 1941.

6. Cartwright, D. \& Zander, A. (Eds.) Group dynamics. Evanston, Ill. : Row, Peterson, 1953.

7. Centers, R. The psychology of social classes. Princeton, N. J.: Princeton Univ. Press, 
1949.

8. Chiwa, H. (Ed.) Sacial psychology. Tokyo: Seishin shobo, 1957.

9. Fromm, E. Escape from freedom. New York: Rinehart, 1941.

10. Fromm, E. Man for himself; an inquiry into the psychology of ethirs. New York: Rinehart, 1947.

11. Fromm, E. Psychoanalysis and religion. New Heven, Conn.: Yale Univ. Press, 1950.

* 12. Fujino, T., Okaji, J., \& Fukushima, M. A factorial study of social attitudes. Res. Rep. of Hokkaido Educ. Univ., 1953, 4, No.2.

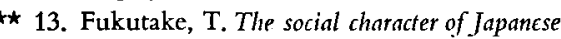
peasants. Tokyo: Tokyo Univ. Press, 1953.

$\star$ 14. Furuya, T. An experimental study on the resistance to the change of attitude - The resistance in relation to the degree to which attitude anchor in a group-norm. Jap. J. Psychol., 1958, 28, 260-268.

* 15. Hirota, K. Experimental study of competition. Jap. J. Psychol., 1951, 21, 70-81.

$\star$ 16. Hirota, K. Group problem solving and communication Jap. J. Psychol., 1953, 24, 1.05-113.

* 17. Hirota, K. Social psychological study of minority group. Human Science (Saikyo Univ. Res. Rep.), 1954, No. 5, 111-128.

* 18. Hirota, K. The further investigation of sociometry. Jap. Psychol. Rev., 1958, 2, 113133.

19. Homans, G. C. The human gronp. New York: Harcourt, Brace, 1950.

20. Hovland, C. I., Janis, I. L., \& Kelly, H. H. Communication and persuasion; psychological studies of opinion change. New Haven, Conn.: Yale Unive. Press,1953.

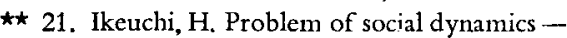
An attempt of social psychological study. Jap.J. Psychol., 1949-50, 20, 22-29.

$\star \star 22$. Ikeuchi, $H$. The present and future problems in mass communication research. Jap. Psychol. Rev., 1959, 3, 1-15.

$\star \star 23$. Imada, M. The psychology of attitudes, in its general trends in contemporary psychology. Jap. J. Psychol., 1944, 19, 173-176.

$\star \star 24$. Inaba, S. Mass audience - One aspect of modern culture-Jap. Psychol. Rev., 1959, 3, 35-41.

$\star \star 25$. Ito, Y. Social psychology. Tokyo: Rishosha, 1949.

$\star \star 26$. Kamitake, S. Conditional genetic study of leadership process in children groups
(1) - Psychological study of leadership Jap. J. Psychol., 1941, 16, 352-380.

^27. Kamitake, S. Conditional genetic study of leadership process in children groups. (2) Jap. J. Psyclol., 1942, 17, 93-132. ; (3) Jap. J. Psychol., 1942, 17, 296-320.

$\star 28$. Kaneko, H. et al. On the friendship in the classmate of school children (1). Iap. J. Psychol., 1931, 6, 223-247.

*29. Kanematsu, R. The mutual relation of workers in cooperative performance. Jap. J. Psychol., 1956, 26, 326-332.

$\star \star 30$. Kano, T. Some problems of social psychology in recent time. Jap. J. Psychol., 1931, 6, 425-437.

$\star \star 31$. Kinoshita, T. The study of rumor: its approach and review of research methods. Jap. Psychol. Rev., 1957, 1, 132-156.

$\star 32$. Kishida, M. A study on the effects of group norm upon the change of opnion. Jap. J. Psychol, 1956, 27, 106-110.

$\star 33$. Kitawaki, M. On the quantification of group cohesiveness in industrial society by sociometric test. Jap. J. Psychol, 1956, 26, 386-392.

* 34. Kobayashi, S. Problems of group leadership. Child Study, 1947, 2,No, 2.

$\star 35$, Koga, Y. Measurement of attitudes toward sport. Jap. J. Psychol., 1934, 9, 953-977.

$\star \star 36$. Kondo, T. An experimental study of social psychology. Jap. J. Psycho!., 1929, 4, 635-670.

$\star \star 37$. Kondo, T. On the experimental method of social psychology. Jap. J. Psychol., 1930, 5, 759-769.

$\star \star 38$. Kondo, T. In the course of the new social psychology - To Mr. T. Kano, and $H$. Kaneko. Jap.J. Psychol., 1931,6,611-622.

$\star \star 39$. Kondo, T. Social psychology. Tokyo: Asakurashoten, 1956.

40. Lasswell, H. D. Power and personality. New York:Norton, 1948.

41. Lewin, K. Principles of topoyical psychology. New York:McGraw-Hill, 1936.

42. Lewin, K. Resolving social conflicts. New York:Harper, 1948.

43. Lewin, K. Field theory in social science. New York:Harper, 1951.

44. Lindzey, G. (Ed.) Handbook of social psychology. (2 vols.) Cambridge: AddisonWeseley, 1954.

45. Iinton, R. (Ed.) Science of man in the world crisis. New York: Columbia Univ. 
Press, 1945.

46. Linton, $\mathrm{R}$. The ctulural baikground of personality, London : Routledge \& Kegan Paul, 1945.

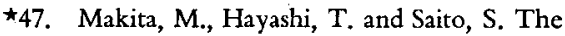
study of politial party affiliation. Jap. J. Psychol., 1959, 29, 377-395.

$\star \star 48$. Matsumoto, H. An experiment in social influences. Jap. J. Psychol.,1930, 6, 503-520.

$\star \star 49$ Matsumoto, H. Social influence (III) - The process of discussion and its effects upon the opinion of members of discussing group. Jap. J. Psychol., 1936, 10, 79-106.

*50 Matsuyama, Y., Tanaka, K. The measurement of the social attitude (III) - On the type-factors in the social attitude - Jap. J. Psychol., 1954, 25, 174-180.

51. Maier, N. R. F. Principle of human relations. NewYork : Wiley, 1952.

52. Mills, C. W. White color: The American middle class. New York: Oxford Univ. Press, 1951.

53. Mills, C. W. The power elite. NewYork: Oxford Univ. Press, 1956.

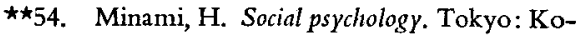
bunsha, 1949.

$\star \star 55$. Minami, H. Psychology of Japanese people. Tokyo: Iwanami shoten, 1953.

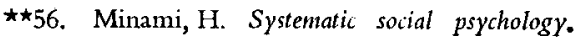
Tokyo: Kobunsha,1957.

$\star \star 57$. Miyagi, O. A note on social psychology. Tokyo, Kawadeshobo, 1955.

*58. Mizuhara, T. \& Tamai, S. Experimental studies of cooperation and competition (I) The effects upon the cohesiveness of group. Jap. J. Psychol., 1952,22, 48-51.

*59. Mizuhara, T. Experimental studies of cooperation and competition(II) - The effects upon the change of opinion. Jap. J. Psychol., 1952, 23, 170-172.

$\star \star 60$ Nagashima, S. Social psychology of children. Tokyo: Maki-shoten, 1957.

*61. Nakamura, Y. Study of group stratification. Jap. J. Psychol., 1952, 23, 1-11.

*62. Nakanishi, N. et al. Psychological study of the parent-child relationship - Experimental study of social behavior. Res. Rep. of Osaka City Univ., 1955, 2, No. 5.

63. Newcomb, T. M. Social psycholoy. NewYork : Dryden Press, 1950.

${ }^{\star}{ }^{6} 64$. Nishihira, S. \& Suzuki, T. The effects of mass communication. Jap. Psychol, Rev., 1959, 3. 48-60.
*65. Nishiyama, S. A study of the effect of discussion on group decision. Jap.J. Psychol, 1959, 30, 111-112.

*66 Nomura, A. Social Psychological approach to a minority group. Educ. Sci. Rep. of Shimane Univ., 1957, No. 7, 43-58.

$\star \star 67$. Nomura, A. The consistency of social attitude. Educ. Sci. Rep. of Shimane Univ., 1958, No. 8, 11-23.

*68. Ohashi, M. Studies on choice behavior and interpersonal perception (I) - Perception of feelings in others and their choice status. Jap. J. Psychol, 1956, 27, 36-45.

*69. Ohashi, M. Studies on choice behavior and interpersonal perception (II) -- Perception on the other person's attitude towards the third person. Jap. J. Psychol., 1956, 27, 193-203.

^70. Ohashi, M. Studies on choice behavior and interpersonal perception (III) - Factor of group structuralization in relationperception. Jap. J. Psychol., 1958, 29, 235245.

$\star \star 71$. Okabe, K. The political consciousness Its relation to mass media. Jap. Psychol. Rev., 1959, 3, 42-47.

$\star 72$. Okano, M. Group structure and personality of members. Jap. J. Psychol., 1956, 27, 8-14.

*73. Ota, N. A study on self-control mechanisms of discussion groups(1). Jap. J. Psychol.,28, 74-85.

$\star \star 74$. Ota, H. The effects of feedback in group location. Jap. J. Psychol., 1956, 26, 333-335.

75. Parsons, T. Toward a general theory of action. Cambridge;Harvard Univ.Press,1951.

76. Riesman, D. Lonely crowd, the study of changing American character. 1950.

^77. Sano, K. \& Sekimoto, M. Group activities in experimentaily created hierarchy groups. Study Rep. of Res. Inst. of Mental Medicine, 1955, No. 2.

78. Sato, K, and Nakane, F. Nationality preferences of Japanese students after World War II. J. soc. Psychol., 1948, 28, 165-166.

79. Sherif, M. An outline of so.ial psychology, (rev.) New York: Harper, 1956.

$\star \star 80$. Shimizu, I. Socinl psychology. Tokyo: Iwanamishoten, 1951.

$\star \star 81$. Sotobayashi, T. et al. Social psychology. Tokyo: Seishin-Shobo, 1956.

$\star \star 82$. Suenaga, T. Basic problems of social psychology. Psukhe, 1947, 1, No. 1, 13-20. 
$\star \star 83$. Suenaga, T. Psychology and field theory -investigation of Lewin's theory-Psukhe , 1949, 1, No. 5, 1-8.

$\star \star 84$. Takase, $T$. The concept of environment in social psychology. Jap. J. Psychol., 1952, 23, 49-56.

$\star 85$. Tanaka, $K$. The measurement of the social attitude. (I). Jap. J. Psychol., 1954, 24, 96104.

*86. Tanaka, K. The mesurement of the social attitude (II). Jap. J. Psychol., 1954, 24, 277284.

*87. Tanaka, K. \& Matsuyama, Y. The mesurement of social attitude (IV) $-\mathrm{R}$ and $\mathrm{T}$ factor-Jap. J. Ps ychol., 1955.26,141-147.

* 88. Tanaka, K. \& Matsuyama, Y.The quantita- tive research in the culture pattern of Japan. Jap. J. Psychol., 1958, 29, 105-114.

$\star \star 89$. Tanaka, Kum. Social psychology children group. Tokyo:Meiji-toshoshuppan, 1957.

$\star \star 90$. Tanaka,Kum. Theory and methods sociometry. Tokyo: Meiji-toshoshuppan, 1959.

$\star 91$. Toki, H. The leader follower structure in the school-class. Jap. J. Psychol., 1935, 10, 27-56.

*92. I'suzuki, A. \&Ota, M. A study on self-control mechanisms of group(II). Jap. J. Psychol., 1958, 29, 253-263.

* Articles written in Japanese with English summary.

$\star \star$ Articles written in Japanese. MS. received $X 23,59$.

Kimiyoshi Hirota (広田君美 1924-), graduated from Kyoto Univ. in 1950. 1950-1953, Research fellow in graduate school, Kyoto Univ.; 1953-1959, Lecturer to assistant professor, Saikyo Univ., 1259Assistant professor \& Research associate of Institute of Social Research, Kansai Univ.

Publication-books: The dynamics of classroom group. (co-work) 1953, Kanekoshoten. Industridl psychology. 1957, Sanwashobo. Psychology of intergroup relation. (co-work) 1957, Meijitosho. Articles: Experimental study of competition. 1951. Group problem solving and communication. 1953. Psychological study of minority group. 1953. Competition and cooperation. 1958. The further investigation of sociometry. 1958. Social interests: Group dynamics, communication, culture and personality, and humman relations in industry.

\section{NEWS OF THE WORLD (I)}

The International Conference on Education was held in Tokyo and Kyoto on August 31September 11, 1959. About forty educationists came to attend from the U. S., Canada, Belgium, England, France, Germany, Sweden, Saudi Arabia, China and Korea. It was a great pleasure for us to find Prof. Maurice Debesse from the University of Paris among them.

The First Meeting of the Japanese Association of Educational Psychology was held on October 31-November 1, 1959, in the University of 'Tok yo. The Japanese Association of Educational Psychology had been publishing the Japanese Journal of Educational Psychology for seven years, but considering the possibility to be integrated into the Japanese Psychological Association, together with the Japanese Association of Applied Psychology, its managing committee was hesitating to have an independent meeting. But the plan of integrating all the main psychological associations in Japan turn- ed out to be unsuccessful last summer, the Association decided itself to go its own way. Among eighty reports, a comparative psychological study of character formation in England, France, Germany and Japan, conducted by Prof. Y. Ushijima and others of Kyushu University, was very instructive, and the editor hopes to have their contribution to Psychologia in the near future.

The Soc ety for the Investigation of Human Ecology, which was founded in 1955, have supported a number of researches in that field, chiefly in the United States, but some in other areas, such as a part of the Hungarian studies conducted at the University of Nijmegen, the Netherlands. Those who wish to inquire about the Society grants or fellowship should write to "Executive Secretary, Sosiety for the Investigation of Human Ecology, 71-58 Austin Street, Forest Hills 75, L.I., N. Y., U. S. A." 